\title{
Biomaterials used in Reduction and Fixation of Unstable Fractures of the Zygomaticomaxillary Complex
}

\author{
CRISTIAN BUDACUㅍ, ALEXANDRU NEMTOI ${ }^{2 *}$, MIHAI CONSTANTIN ${ }^{1 *}$, MARIUS CRISTIAN MARTU ${ }^{3 *}$, DANISIA HABA ${ }^{1}$ \\ ${ }^{1}$ Grigore T. Popa University of Medicine and Pharmacy, Department of Oral and MaxilloFacial Surgery, Faculty of Dental Medicine, \\ lasi, Romania \\ ${ }^{2}$ Grigore T. Popa University of Medicine and Pharmacy, Department of Anatomy, Faculty of Medicine, Iasi, Romania \\ ${ }^{3}$ Grigore T. Popa University of Medicine and Pharmacy, Department of ENT, Faculty of Medicine, Iasi, Romania
}

\begin{abstract}
This study evaluated a series of cases of fracture in the zygomaticomaxillary complex with displacement of the fractured segment which were evaluated before and after treatment with cone beam CT. The treatment perfomed was represented by titanium micro-plates and screws. The study sample which consist of 25 patients of both genders with fractures in the zygomaticomaxillary bones. After clinical examination to arrive at correct diagnosis and treatment plan, each patient was subjected to $2 \mathrm{D}$ and $3 \mathrm{D}$ reconstruction using cone beam CT. Reffering to the type of treatment was evaluated the procces of bone remodelling and also the osseointegration process of the titanium micro-plates and screws used for reduction and fixation of the fractures. The treatment performed for all patients was reduction and fixation with titanium microplates which were osseointegrated partially in $45 \%$ of patients and 3 screws were not osseointegrated.
\end{abstract}

Keywords: biomaterials, titanium, fracture, cone beam computed tomography

Trauma is the public health problem with the greatest po-tential to be prevented and treated. Thus, understanding the cause and severity of maxillofacial traumatic lesions may contribu-te to the establishment of clinical and research priorities for the effective treatment and prevention of these inju-ries [1]. Trauma is among the leading causes of death and morbidity in the world, accounting for $7.4 \%$ to $8.7 \%$ of emergency care [2].

The increase in the level of life expectan-cy, urban growth and its forms of locomotion, unemploy-ment crises and the consumption of alcohol and drugs in the different regions, alter the age, gender, etiology and frequency of facial lesions [3].

The zygomaticomaxillary complex (ZMC) is a major buttress of the midfacial skeleton. The ZMC is important to structural, functional, and aesthetic appearances of the facial skeleton. A ZMC fracture is also known as a tripod, tetrapod, or quadripod fracture, trimalar fracture or malar fracture [4,5]. Management of ZMC fractures is a frequent challenge in oral and maxillofacial surgery.

The surgical approach is devised based on the findings from the physical examination and imaging studies. Adequate exposure and mobilization of the fracture fragments are critical for ensuring appropriate anatomical reduction. The most essential criteria for the successful treatment of zygomaticomaxillary fractures are accurate reduction and the three-dimensional stability of the displaced fracture to achieve favorable aesthetic and functional results $[6,7]$

Titanium micro-plates and screws are used regularly for the rigid fixation of zygomaticomaxillary fractures. However, certain disadvantages including the possibility of implant exposure, palpable implant, screws loosening, pain sensation, cold intolerance, and radiographic artifacts still exit $[8,9]$. Some patients require secondary operation to remove plates, and the removal rate is $22.7 \%[10,11]$.

Now days, also exist bioresorbable plates which right now are more expensive which do not need the secondary stage of removing.
The prominence of the zygomaticomaxillary complex (ZMC) convexity along the anterolateral portions of the face makes it vulnerable to traumatic injury. While there is debate as to what part of the facial skeleton is most commonly injured, ZMC fractures comprise up to $40 \%$ of facial fractures $[12,13]$.

Common etiologies include motor vehicle accidents, assault, falls, and sports-related injuries [12, 14] .

The complex three-dimensional aspect of the zygoma contributes both to facial aesthetics and function. It forms the malar eminence, providing cheek projection, and the lateral and inferior portions of the orbit. Reestablishing preinjury form is the goal of all ZMC fracture treatments, regardless of the approach utilized.

As surgical technique and technology have improved through the past century, management opinions have evolved [15-18]. Standard treatment mostly involves internal fixation with titanium micro-plates and screws, but there is much debate regarding what qualifies as adequate fixation.

Three-point fixation for treatment of ZMC fractures is traditionally recommended; however, there are varying opinions on what is truly necessary for adequate reconstruction [17, 19-23]. Despite the prevalence of ZMC fractures, there is no consensus in the literature concerning the best approach to management and when repair is indicated.

Because of its functional and cosmetic importance, facial injuries, especially bony fractures are clinically very significant. Missed and maltreated fractures might result in malocclusion and disfigurement of the face, thus making accurate diagnosis of the fracturevery essential.

In earlier times, conventional radiography along with clinical examination played a major role in diagnosis of maxillofacial fractures. Nowadays, we have acces to 3D investigation which help the surgeons for 3D reconstructions.

This study evaluated a series of cases of fracture in the zygomaticomaxillary complex with displacement of 

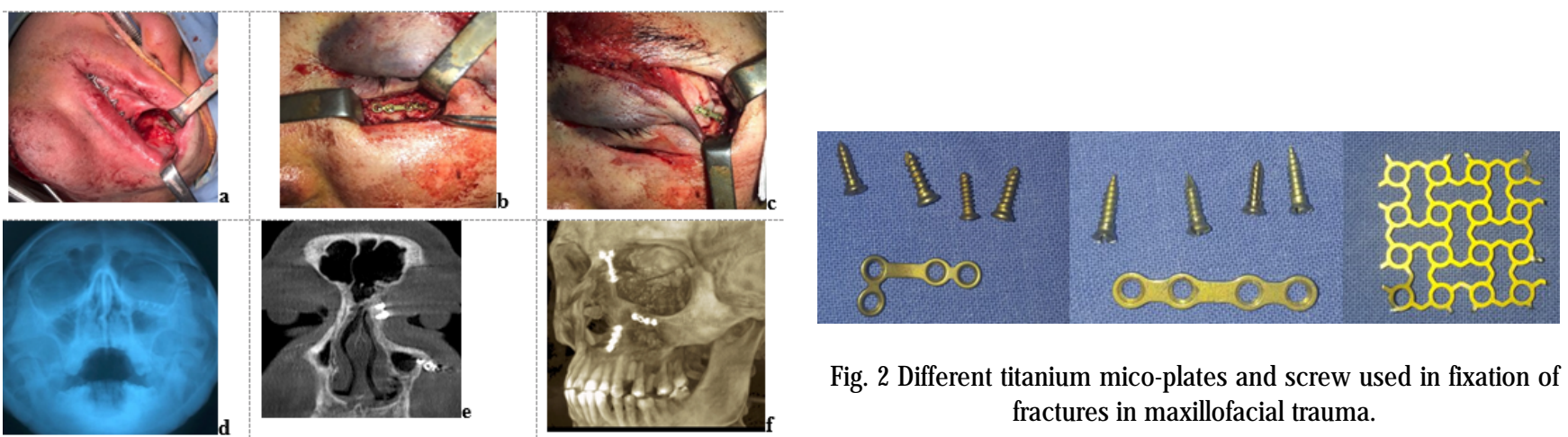

Fig. 2 Different titanium mico-plates and screw used in fixation of fractures in maxillofacial trauma.

Fig. 1 Different types of approaches for reduction and fixation with titanium micro-plates and screws in zygomaticomaxillary complex

fractures $(a, b, c), X$-ray view of the biomaterials used in osteosynthesis, antero-posterior view of the skull (d), 2D and 3D

$\mathrm{CBCT}$ reconstruction showing the fracture and adequacy of reduction $(e, f)$

Table 1

SCORING SYSTEM FOR ASSESSMENT OF THE DEGREE OF FRACTURE DISPLACEMENT AND ADEQUACY OF REDUCTION

\begin{tabular}{|lcc|}
\hline Score $\mathbf{0}$ & $\mathbf{l}$ & \multicolumn{2}{c|}{$\mathbf{2}$} \\
\hline $\begin{array}{l}\text { Preoperative } \\
\text { Segmental or comminuted displacement }\end{array}$ & Minimal displacement & Moderate displacement \\
\hline $\begin{array}{l}\text { Postoperative } \\
\text { after using }\end{array}$ & Adequate reduction and union & Mild displacement and nonunion \\
$\begin{array}{l}\text { micro-plates } \\
\text { Inadequate reduction }\end{array}$ & \\
\hline
\end{tabular}

the fractured segment which were evaluated before and after treatment with cone beam CT.

The treatment perfomed was represented by titanium micro-plates and screws and the biological effect of these biomaterials was observed.

\section{Experimental part}

This prospective study was conducted between July 2016 and September 2017. The study sample which consist of 10 patients of both genders with fractures in the zygomaticomaxillary bones in a control group which received a treatment without using titanium plates and 15 patients of both genders with fractures in the zygomaticomaxillary bones in a group with received treatment using titanium plates.

The collection instrument included a specific sheet with data concerning the patient's age, cause, side of the fracture, type of treatment performed and recurrence. After clinical examination to arrive at correct diagnosis and treatment plan, each patient was subjected to 3D reconstruction using cone beam $\mathrm{CT}$.

Reffering to the type of treatment was evaluated the procces of bone remodelling and also the osseointegration process of the titanium micro-plates and screws used for reduction and fixation of the fractures. The data were presented by means of descriptive statistics. Patients with simple zygomatic arch fracture, comminuted fracture at each junction of zygoma and other facial bone, and multiple midfacial fractures were excluded in this study.

The fracture site is explored through the gingivobuccal incision (fig. 1). After achieved adequate reduction, fixation is performed with titanium micro-plates (fig.2) at the lateral buttress, and this is the first fixation point. If fixation was not rigid or reduction was not adequate during operation, it is necessary to explore other fracture sites for the second or third fixation points.

We created an infracilliary incision to approach the infraorbital rim and a cutaneous incision to approach the zygomatic ofrontal junction (fig. 1). The infraorbital rim is the typical second fixation point and followed by the zygomaticofrontal junction if necessary. All the surgical procedures were performed by a single surgeon to avoid surgical bias.

For evaluation the fracture displacement and adequacy of fracture reduction, we developed a cone beam computed tomography (CBCT) scan scoring system. Five anatomic points with the total score range from 0 to $10(0$ -2 for each point).

A score of 2 represented the most comminuted preoperative displacement and inadequate reduction of more than $2 \mathrm{~mm}$ after operation. A score of 1 indicated fracture displacement of less than $2 \mathrm{~mm}$ or nonunion (absence of calcified bone crossing the fracture site).

A score of 0 represented a minimal to nondisplaced fracture line preoperatively and accurate alignment with bone union postoperatively.

Four evaluation points, including the zygomaticofrontal junction, inferior orbital rim, zygomatic arch, and lateral buttress, were assessed in a series of CBCT scans preoperatively and 6 months postoperatively (table 1).

The outcome of postoperative score of the titanium micro-plate were evaluated using the t-test for unpaired comparisons. For each test, a $p$ value $<0.05$ is considered statistically significant.

\section{Results and discussions}

Both the titanium plate and the control - without titanium plate groups included patients with a follow-up CBCT at least 6 months. The mean of patient age in the control and titanium plate groups were 35 years and 33 years, respectively. The male-to-female ratios were 1.7:1 and 1.4:1 in the control and titanium plate groups, respectively. $\mathrm{C}$

omorbidity, associated injury, and trauma mechanisms were comparable between the groups. In both groups, the initial symptoms included malar depression with numbness in the territory of the infraorbital nerve in all patients. In addition, 8\% diplopia and 3\% enophthalmos were observed in the control group. By contrast, $18 \%$ diplopia and 21\% enophthalmos were observed in the titanium plate group. 


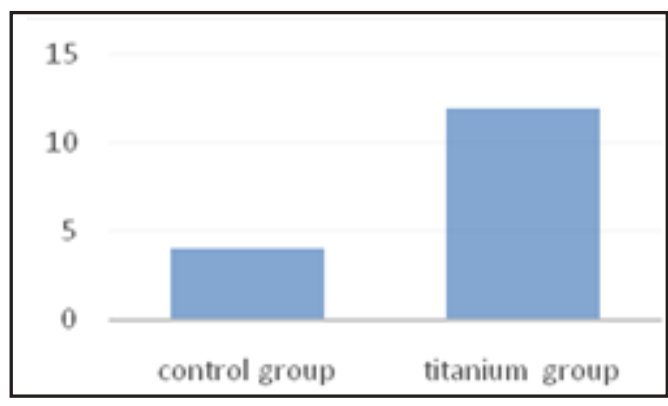

Fig. 3 Descriptive results of positive reduction and fixation of fracture between the control group and the titanium micro-plates group

The average preoperative CBCT scan scores of the control group were 4.5 (38\% of patients), $4.9(45 \%)$, and $5.3(8 \%)$ for the one, two, and three points fixations, respectively. By contrast, the average preoperative CBCT scan scores of the titanium plate group were $3.5(35 \%)$, $5.4(52 \%)$ and $5.2(5 \%)$ for the one, two and three points fixations respectively. The average operation time for the titanium plate group was 30 min longer than that for the control group.

In addition, the average implant cost of the titanium plate group was 5.8 higher than that of the control group. The complications included palpable implant, hypersensitive cheek, skin irritation, and ectropion. The complication rate was similar in both groups. The maximal mouth-opening function was higher in the titanium plate group in the first 3 postoperative months, but a similar function was observed in both groups in the first 6 postoperative months. The appearance satisfaction was assessed in both groups at 1, 3, and 6 months postoperation. No case in either group required a secondary procedure for removing the implant during the follow-up period of 6 months.

The most frequent etiology was a motorcycle accident $(67.0 \%)$ and the left side was more affected (80.0\%). The treatment performed for the patients from the studied group was reduction and fixation with titanium miniplates which were osseointegrated partially in $45 \%$ of patients and 3 screws were not osseointegrated.

The most common indication for surgery in ZMC fractures is displacement and rotation, and most displaced ZMC fractures should be treated surgically. If reduction is not performed properly, facial asymmetry will be prominent, as the result of lowering the malar prominent point [5]. For this reason, precise anatomical reduction is very important.

A randomized study compared the treatment outcomes and complication rates in patients with displaced zygomatic fractures [24]. The patients were divided, on the basis of the fixation material, into 4 groups ( $A$ : LactoSorb, total number of patients $n=15$; B: BioSorb, $n$ $=17$; C: DeltaSystem, $n=17$; and D: Titanium, $n=15$ ), whereas patients with comminuted zygomatic fractures were excluded. No difference was observed in the handling characteristics of the 3 materials (LactoSorb $1.5 \mathrm{~mm}$, BioSorb FX $1.5 \mathrm{~mm}$, and DeltaSystem $1.7 \mathrm{~mm}$ ) [24].

In a study, 65 patients with isolated unilateral zygomatic fracture fixed with Lactosorb plates and screws were included [25]. Thirty patients received the first fixation point at the zygomaticomaxillary buttress and all patients showed a high postoperative symmetry [25].

The short-term complication rate was $22.8 \%$ and included complications such as intraoral dehiscence with or without implant exposure, temporary swelling, and ectropion. Five patients had a long-term complication of ectropion, whereas no implant-related complications were observed in the long-term follow-up period. Thus, the authors reported that bioabsorbable osteosynthesis materials can be considered additional tools, but not for the replacement of conventional metal osteosynthesis materials [26].

Furthermore, the titanium micro-plates group had a higher functional outcome and patient satisfaction rate as the control group. The advantage of the titanium microplates is that it can avoid complications in reduction and fixation the fracture, it is biocompatible and present very low artefacts in CBCT exams.

\section{Conclusions}

Fractures in the zygomaticomaxillary complex are more frequent in young male individuals and the most common cause is a motorcycle accident, with the use of titanium micro-plates and screws constituting an effective treatment without recurrence. This research provides data for a better understanding of the neccesary of titanium micro-plates and screws used in facial fractures and the utillity of CBCT exams for assessment of the degree of fracture displacement and adequacy of reduction.

\section{References}

1.GASSNER R, TULI T, HACHL O, MOREIRA R, ULMER $H$. Craniomaxillofacial trauma in children: a review of 3,385 cases with 6,060 injuries in 10 years. J Oral Maxillofac Surg. 2004;62(4):399-407.

2. BARKER R, HOCKEY R, SPINKS D, MILES E. Facial Injury. Injury Bulletin Queensland Injury Surveillance Unit. 2003;79:1-6

3. BANKS P. Killey's fraturas da mandíbula. $4^{\text {th }}$ ed. Sao Paulo: Santos; 1994.

4. Ellstrom CL, Evans GR. Evidence-based medicine: zygoma fractures. Plast Reconstr Surg 2013;132:1649-57.

5. MESLEMANI D, KELLMAN RM. Zygomaticomaxillary complex fractures. Arch Facial Plast Surg 2012;14:626.

6. O'HARA DE, DEL VECCHIO DA, BARTLETT SP, ET AL. The role of microfixation in malar fractures: a quantitative biophysical study. Plast Reconstr Surg. 1996;97:345-350.

7. RINEHART GC, MARSH JL, HEMMER KM, ET AL. Internal fixation of malar fractures: an experimental biophysical study. Plast Reconstr Surg. 1989;84:21-25.

8. FRANCEL TJ, BIRELY BC, MANSON PN, ET AL. The fate of plates and screws after facial fracture reconstruction. Plastic Reconstr Surg. 1992; 90:568-573.

9. CHRISTOPHER E, GREGORY E. Evidence-based medicine: zygoma fractures. Plastic Reconstr Surg. 2013;132:1649-1657.

10. MOSBAH MR, OLOYEDE D, KOPPEL DA, ET AL. Miniplate removal in trauma and orthognathic surgery - a retrospective study. Int J Oral Maxillofac Surg. 2003;32:148-151.

11. NAGASE D, COURTEMANCHE D, PETERS D. Plate removal in traumatic facial fractures: 13-year practice review. Ann Plast Surg. 2005;55:608-611.

12. BHATT V, CHHABRA P, DOVER MS. Removal of miniplates in maxillofacial surgery: a follow-up study. J Oral Maxillofac Surg. 2005;63:756-760.

13. BOGUSIAK K, ARKUSZEWSKI P. Characteristics and epidemiology of zygomaticomaxillary complex fractures. J Craniofac Surg 2010; 21(4):1018-1023

14. MARINHO RO, FREIRE-MAIA B. Management of fractures of the zygomaticomaxillary complex. Oral Maxillofac Surg Clin North Am 2013;25(4):617-636

15. ELLIS E III, EL-ATTAR A, MOOS KF. An analysis of 2,067 cases of zygomatico-orbital fracture. J Oral Maxillofac Surg 1985;43(6):417-428 16. FONSECA RJ, BARBER HD, POWERS MP, FROST DE. Oral andMaxillofacial Trauma. Saint Louis, MO: Elsevier Health Sciences; 2013:354-450 
17. ROWE N, KILLEY H. Fractures of the Facial Skeleton. Baltimore, MD:Williams \& Wilkins; 1955:205-451

18. ELLIS E III, KITTIDUMKERNG W. Analysis of treatment for isolatedzygomaticomaxillary complex fractures. J Oral Maxillofac Surg 1996;54(4):386-400, discussion 400-401

19. CZERWINSKI M, MARTIN M, LEE C. Quantitative comparison of open reduction and internal fixation versus the Gillies method in the treatment of orbitozygomatic complex fractures. Plast Reconstr Surg 2005;115(7):1848-1854, discussion 1855-1857

20. CHOI KY, RYU DW, YANG JD, CHUNG HY, CHO BC. Feasibility of 4point fixation using the preauricular approach in a zygomaticomaxillary fracture. J Craniofac Surg 2013;24(2):557-562

21. CHAMPY M, LODDE JP, KAHN JL, KIELWASSER P. Attempt at systematization in the treatment of isolated fractures of the zygomatic bone: techniques and results. J Otolaryngol 1986;15(1):39-43

22. FUJ IOKA M, YAMANOTO T, MIYAZATO O, NISHIMURA G. Stability of one plate fixation for zygomatic bone fracture. Plast Reconstr Surg 2002;109(2):817-818
23. HOLMES KD, MATTHEWS BL. Three-point alignment of zygoma fractures with miniplate fixation. Arch Otolaryngol Head Neck Surg 1989;115(8):961-963

24. WITTWER G, ADEYEMO WL, ENISLIDIS G, ET AL. Complications after zygoma fracture fixation: is there a difference between biodegradable materials and how do they compare with titanium osteosynthesis? Oral Surg Oral Med Oral Pathol Oral Radiol Endod. 2006;101:419-425.

25. ENISLIDIS G, PICHORNER S, LAMBERT F, ET AL. Fixation of zygomatic fractures with a new biodegradable co-polymer osteosynthesis system: preliminary results. Int J Oral Maxillofac Surg. 1998; 27:352.

26. ENISLIDIS G, LAGOGIANNIS G, EWERS R, ET AL. Fixation of zygomatic fractures with a biodegradable copolymer osteosynthesis system: short and long-term results. Int J Oral Maxillofac Surg. 2005;34:19-26.

Manuscript received: 3.06 .2017 